\title{
The challenge of combatting non-communicable diseases in Trinidad: Access to hospital care
}

\author{
Patricia J. Boda \\ Department of Geosciences, Middle Tennessee State University, Murfreesboro, USA; pat.boda@mtsu.edu
}

Received 4 September 2013; revised 4 October 2013; accepted 17 October 2013

Copyright (C) 2013 Patricia J. Boda. This is an open access article distributed under the Creative Commons Attribution License, which permits unrestricted use, distribution, and reproduction in any medium, provided the original work is properly cited.

\begin{abstract}
Chronic illnesses, or non-communicable diseases (NCDs), account for a growing number of deaths worldwide. The English-speaking Caribbean has the highest per capita burden of NCDs in the region of the Americas [1]. This paper presents an overview of hospital availability on the island of Trinidad in the West Indies and examines rates of NCDs as reported in hospital discharge summaries. The project integrates a Geographic Information System (GIS) with epidemiologic and bio-statistical data to provide essential spatial analysis not otherwise possible. It examines the island's ability to effectively deliver treatment to residents with NCDs by providing a geographic perspective to public data published on the internet by the Trinidad-Tobago Ministry of Health and the Central Statistical Office. The study reveals a significant variability in several dimensions of access to health care.
\end{abstract}

Keywords: Access; Health Care; Caribbean; Trinidad; Non-Communicable Disease

\section{INTRODUCTION}

Communicable or infectious illnesses such as HIV/ AIDS, malaria and tuberculosis continue to consume massive amounts of time, energy and financial resources of many health departments world-wide. However, noncommunicable diseases (NCDs) account for a growing share of total deaths. In fact, heart disease, cancer, chronic respiratory diseases and diabetes are by far the leading causes of mortality in the world, and account for $63 \%$ of all deaths [2]. NCDs tend to be of slow progression and long duration and therefore are very expensive for insurance companies, for health care systems, and for patients. Although the perception is that NCDs primarily affect wealthy nations, nearly $80 \%$ of NCD deaths occur in low- and middle-income countries [1,2].

The English-speaking Caribbean has the highest per capita burden of chronic non-communicable diseases (CNCDs) in the region of the Americas [1]. Cardiovascular disease, cancer, diabetes, and chronic respiratory disease account for $71 \%$ of all deaths in Latin America and the Caribbean in 2008 and that rate is expected to rise from $10 \%$ to $81 \%$ by 2030 [2]. For the most part, these countries have passed through the demographic and epidemiological transition which has resulted in rapidly aging populations who are more prone to chronic illness.

Leaders of several Caribbean nations were convened in Port of Spain, Trinidad in 2007 to discuss the crisis of NCDs in the Caribbean. They developed a decisive plan of action for the reduction of NCDs that became known as the Port of Spain Declaration. The fifteen point commitment plan included a commitment to support initiatives, establish comprehensive plans, establish programs for research, address smoking, address food security, and promote physical activity. The leaders further agreed to have these initiatives in place by 2008.

At a 2011 High Level meeting of the United Nations General Assembly, the organization assessed the capacity of countries to address NCDs, in particular, challenges facing the Small Island Developing States (SIDS). Due to their small size, and typically remote locations, they face a variety of additional challenges associated with limited resources. The small size limits the diversity and volume of natural resources. This results in limited economic resources, limited employment opportunities, and inadequate social services such as health care.

Research regarding health in the Caribbean region often has been linked with health and health care in Latin America with little attention given to the Caribbean as a distinct region with distinct issues and challenges [3-5]. A limited volume of work has been produced on NCDs in the Caribbean that called for increased awareness and prioritization of combatting NCDs [6,7] and strategies to be incorporated into public policy [8]. 
More recently, literature regarding NCDs in the Caribbean has focused on disease-specific studies, in particular, diabetes and hypertension in individual countries $[9,10]$. Others have reported on socioeconomic determinants of health and identified that the elderly and the poor have increased risks for NCDs [9,11]. A considerable amount of attention has been given to patient's perceptions on the quality of care they have received and self-reported incidence of disease [11,14]. In these studies, patients reported varied levels of satisfaction with their clinic and hospital visits. Many reported excessive wait times and too little time with providers. Little, if any attention has been given to the network of hospitals and providers, to variations within one country or to a spatial or geographic approach.

An essential consideration when attempting to reduce NCDs has been conspicuously absent from published research-access to services. This study attempts to fill this void by examining the level of available hospital care based on established health districts. It presents an overview of hospital services on the island of Trinidad. Data were entered into ArcMap and distances and populations to provider ratios were calculated. The process revealed that there were significant differences in access to hospital services among four health districts.

In order to effectively reduce the rate of NCDs, there must be a threefold approach that includes surveillance, prevention, and treatment. Surveillance consists of monitoring exposures (risk factors), monitoring outcomes, and assessing health system capacity and response. Prevention includes addressing exposures (risk factors), education and intervention and treatment examines levels and availability of and access to services.

Access can be a difficult term to define and represents different models to different people. It is a multi-dimensional concept that evaluates the ability of a population to use medical services. Lee 1998 defined access as a product of four variables: 1) availability of services, 2) the possession of the means to access the services such as transportation, insurance or money, 3) non-discriminatory attitudes of providers, and 4) the failure of the ill themselves to cope with the situation via lack of communication, recognition of symptoms and ability to navigate the health system in place [15].

Penchansky and Thomas identified five dimensions that encompassed five specific barriers: availability, accessibility, accommodation, affordability, and acceptability. Availability defines numbers of providers such as physicians, dentists, nurses and other health care workers in relation to the demand for their services. It also includes numbers of hospital beds and services that facilities provide. Accessibility generally describes geographic accessibility and identifies the geographic barriers to receiving such services such as distance, transportation, and travel time to the facility. Accommodation refers to the degree that services meet the needs of patients and include hours of service, waiting times, appointments and scheduling. Affordability discusses the cost of services and acceptability describes how the provider interacts with the patient on a personal level. Acceptability includes potential barriers such as gender, ethnicity, language and sexual orientation and also encompasses patient satisfaction [16]. Each dimension can obstruct access by creating barriers that limit utilization of services. These five dimensions of the Penchansky's model were employed in this study.

\section{DATA SOURCES}

Primary data source for the number of physicians was the Annual Statistical Report compiled by the TrinidadTobago Ministry of Health (MoH) for 2004-2005 [17]. In that report data for four hospitals was contained: Port of Spain General Hospital, San Fernando General Hospital, Sangre Grande and Point Fortin. Due to these limitations, only these four facilities are incorporated in this research.

Community shapefiles containing population figures, hospital locations and number of physicians were made available through the University of the West Indies (UWI) in St. Augustine. This file did not include communities on the sister island of Tobago and as a result, it was excluded from analysis.

Data files were entered and analyzed in ArcMap 10.1.

\section{ACCESS IN TRINIDAD}

Trinidad-Tobago is considered to be a high-income country by the World Bank [18]. The burden of NCDs on small island countries is enormous. In comparing rates of NCD deaths between the United States and Trinidad-Tobago for example, the percentage of total deaths is very similar between the two countries (Table 1).

While the burden may be similar, the capacity to treat these illnesses is not. In Trinidad-Tobago, there are 8 physicians for every 10,000 people, while in the U.S. the number is 26 per 10,000 people. In other words, the U.S. has more than 3 times the medical doctors per 10,000 than

Table 1. Comparison of NCD burden between the U.S. and Trinidad-Tobago, 2010 [1].

\begin{tabular}{ccc}
\hline & Trinidad-Tobago & United States \\
\hline Total NCD & $78 \%$ & $87 \%$ \\
CVD & $34 \%$ & $35 \%$ \\
Diabetes & $14 \%$ & $3 \%$ \\
Cancer & $13 \%$ & $23 \%$ \\
Respiratory & $3 \%$ & $7 \%$ \\
All other NCDs & $14 \%$ & $19 \%$ \\
MDs/10,000 & $8 \%$ & $26 \%$ \\
\hline
\end{tabular}


Trinidad-Tobago despite the fact the disease burden is similar [1].

On the island of Trinidad, there are four health districts and seven hospitals. The locations of the seven hospitals are shown on the following map (Figure 1), along with numbers of physicians and community population concentrations. Communities with higher populations are shown in the darker shades and those with the least population are in the lightest shade.

As mentioned previously, 2005 is the most recent data available on the Ministry of Health $(\mathrm{MoH})$ website and hospital data in that report included only four facilities. They are the public facilities in Port of Spain, San Fernando, Sangre Grande, and Point Fortin [17].
Port of Spain General Hospital has the largest number of physicians with 219, followed by San Fernando with 136, Sangre Grande with 19 and Point Fortin with 9 practicing physicians. Additional facilities not mentioned in the Statistical Report include 4 facilities with a combined number of physicians of 36, three hospitals with 1 physician each. In addition, there is one maternity hospital as well as a mental health facility that were not included in the physician counts for this study.

The district with the highest population is the Southwest district with a population of 500,300, followed by the Northwest district with a population of 414,482, the North Central with 201,549 people, and the eastern district has contains the least number of residents $(101,557)$.

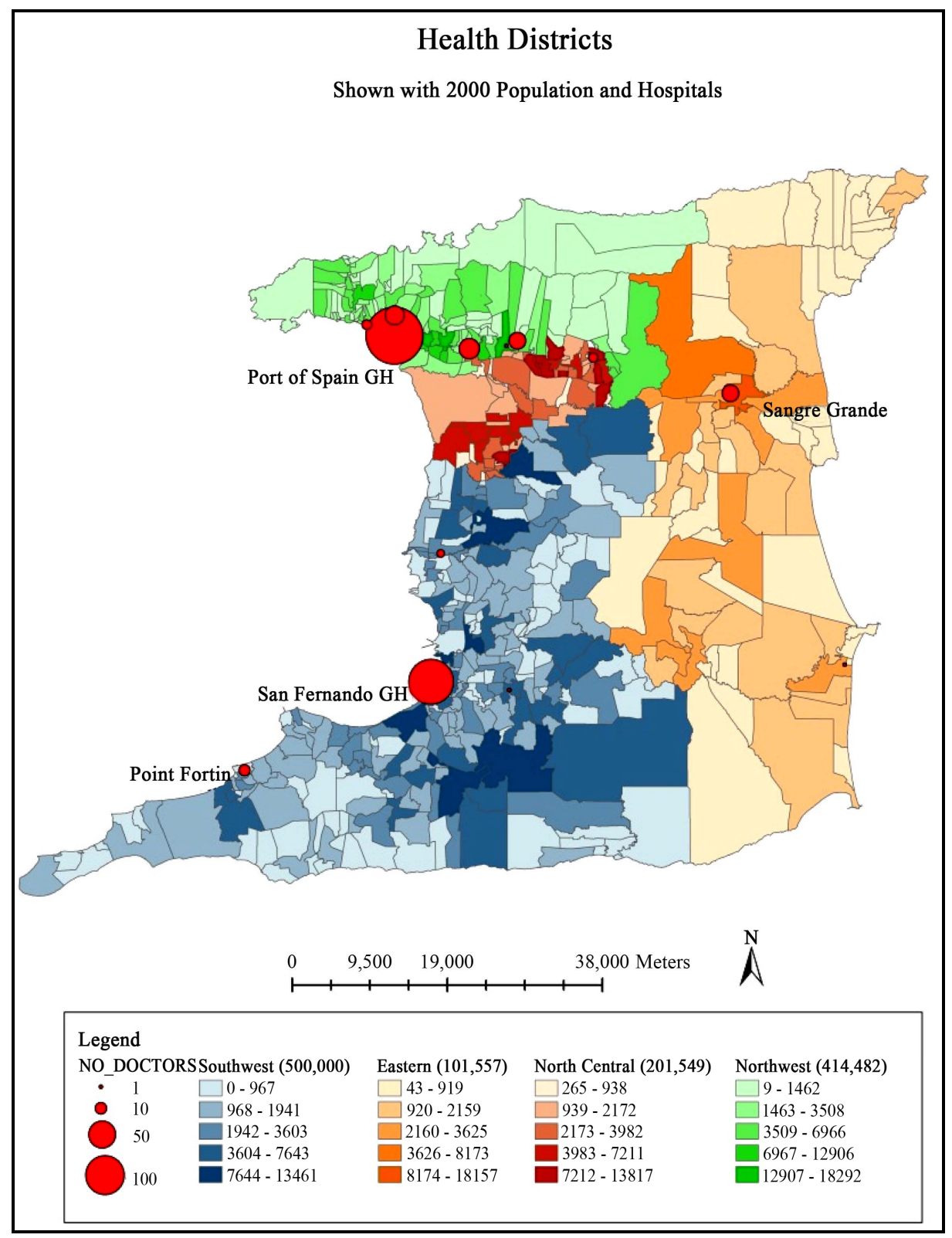

Figure 1. Health districts, providers and community populations. 


\subsection{Availability of Hospitals in Trinidad}

A key question in public health, and included in the Penchansky Model of access is availability of services. One method to determine this is to examine population to provider ratios. According to the Bureau of Primary Health Care (BPHC) in the US, an acceptable level of people per provider is 3500 to 1 , that is, one physician per 3500 people, or potential patients [19]. Population figures and numbers of physicians were compiled by health district and the population to provider ratio for each district was calculated (Figure 2).

As Figure 2 indicates, the lowest ratio is the Northwest, or the Port of Spain district, where there are the most physicians. The highest population to provider ratio is the North Central District with a ratio of over 8000:1. This is somewhat deceptive however because there is a major medical complex located within the boundary, but no hospital. It is interesting to note that the eastern district, with the lowest population, also has a high population to provider ratio at over 5000:1.

\subsection{Geographic Accessibility of Hospitals}

The second dimension of access described by Penchansky is geographic accessibility [16]. The BPHC states that if a population center is within 30 miles or 30 minutes travel time of a provider, that population has satisfactory access to care [19]. Buffer zones of 10, 15 and 20 miles were applied around the four hospitals (Figure 3). At first glance it appears that nearly the entire island is included within the 20 mile zone and therefore has access according to the BPHC definition.

This is misleading however. Although 20 miles is a reasonable distance, the time required to travel the 20 miles on Trinidad roads is considerably more than 30 minutes, which is commonly accepted as the standard [19]. As seen in Figure 3, which displays first class roads on the island, there are a great many sharp turns and twists due to mountainous terrain. Turns and changes in elevation necessitate reducing speed considerably and increases travel time. For example, the community of Tableland, shown in Figure $\mathbf{3}$ as a cross, is located on the 15 mile buffer line from San Fernando Hospital and therefore has a straight-line distance to the facility of 15 miles. The driving distance between these two points was calculated by summing the segments of the primary road between the centroid of the community to the hospital. The actual distance is approximately 29 miles on the first class road of Naparima. This is still within the 30 mile limits set by the BPHC. However, the average speed is approximately 45 miles per hour through the mountainous terrain. At that speed, the trip require approximately 38.6 minutes driving time, which exceeds the BPHC limit for adequate access to health care.

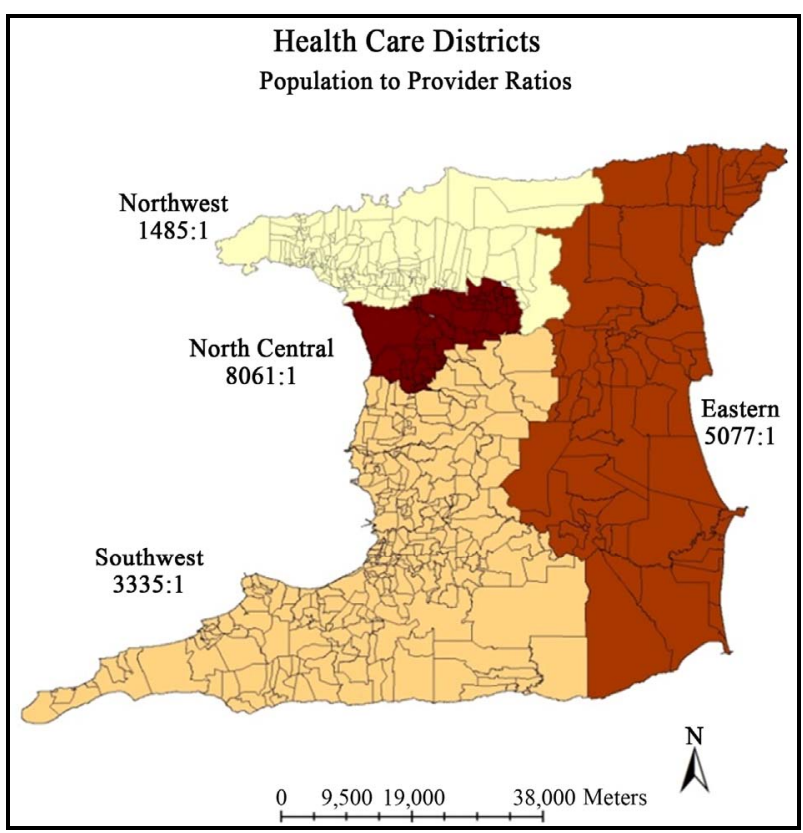

Figure 2. Health districts, providers and community populations.

The total population of communities outside the 15 mile buffer zone was calculated to be approximately 71 , 500 residents. Assuming all residents outside the 15 mile zone have immediate access to a first class road, and assuming driving times are similar throughout the island, a minimum of 71,500 residents of the communities outside the 15 mile buffer zone do not have adequate access to a hospital.

\subsection{NCD Cases by Hospital}

The Annual Statistical Report contains hospital discharge information by department and the International Classification of Disease codes (ICD). The nine leading causes for hospital admission were the same for all four facilities; Port of Spain (PoS), San Fernando (SF), Sangre Grande (SG) and Point Fortin (PF). The tenth illness appeared in some facilities but not others so it was not incorporated into this project. Comparing rates among the nine illnesses among the four main hospitals, the burden of NCDs is evident (Figure 4).

The four leading causes of NCD deaths worldwide, heart disease (also known as cardiovascular disease (CVD), cancer, respiratory disease and diabetes, account for $22.6 \%$ of all hospital discharges at the Port of Spain General Hospital, 28.9\% of discharges at San Fernando General Hospital, $44.2 \%$ at the Sangre Grande facility, and $52.6 \%$ of all discharges at the Port Fortin Hospital.

It is clear that Trinidad experiences substantial rates of NCDs in all areas; however the burden appears significantly higher at the Sangre Grande facility. This health district had a population to provider ratio of 5077:1, and 


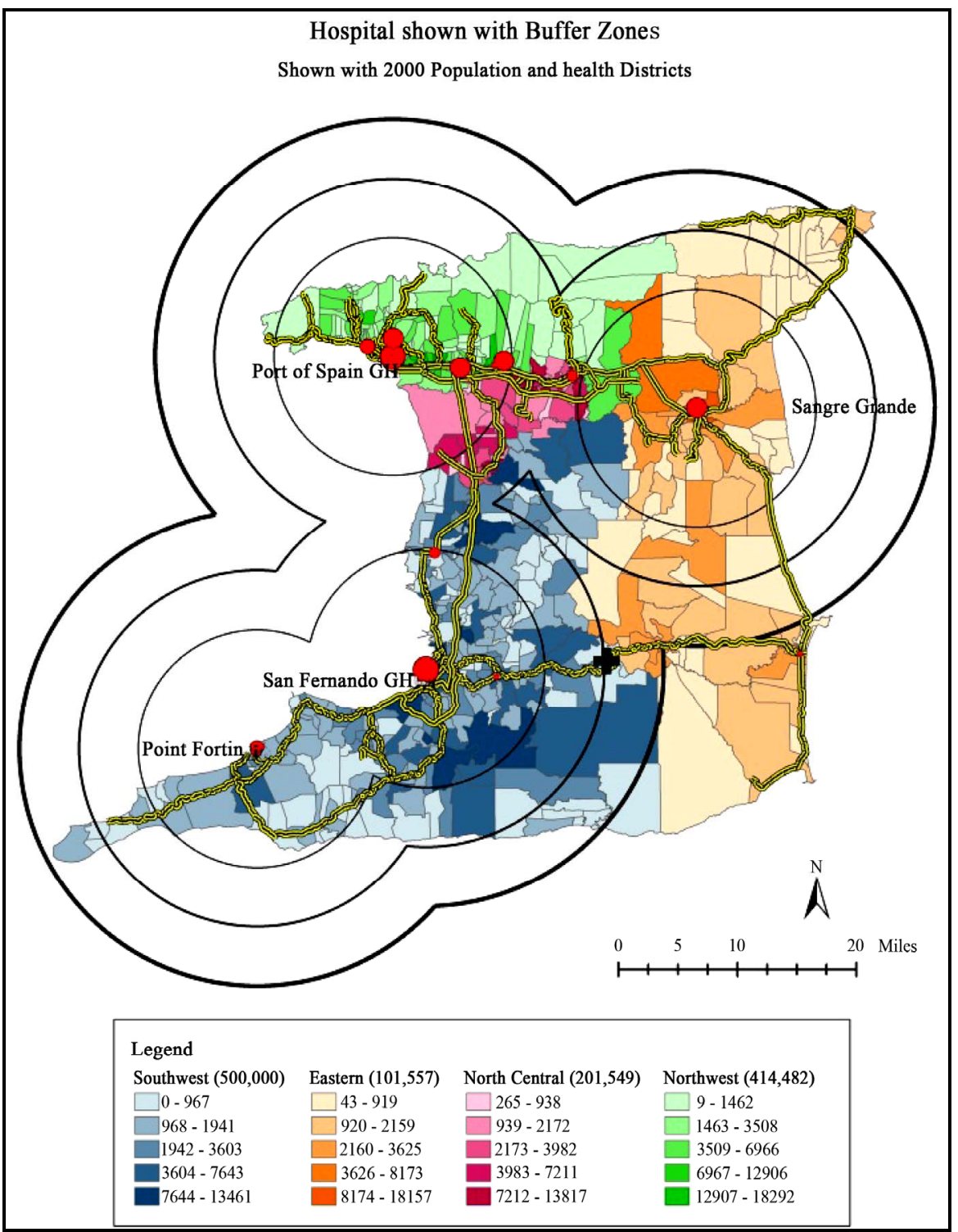

Figure 3. Areas of geographic accessibility.

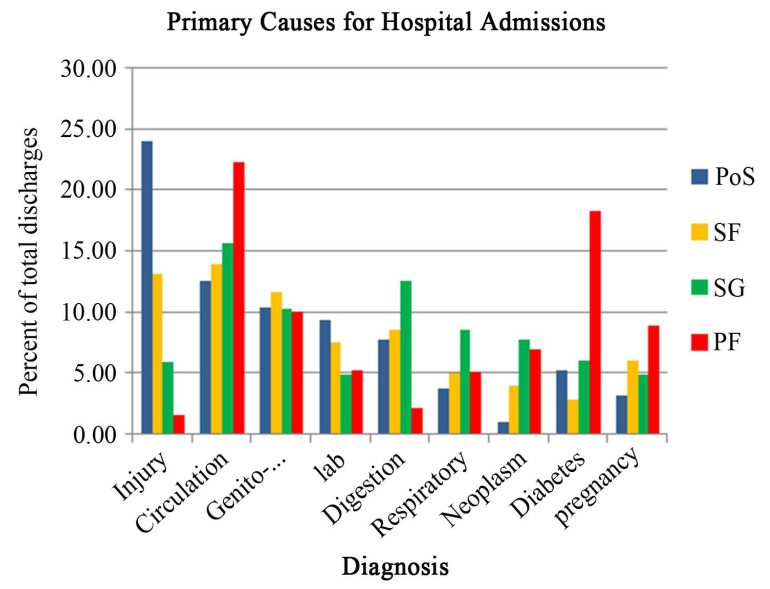

Figure 4. Percentage of hospital discharges for NCDs by facility. is therefore medically underserved according to the defnition used by the BPHC. With only 19 physicians servicing a population of over 96,000 who live in the district, the provider shortage problem is evident.

There also appears to be significant regional variations in reported hospital use. Circulatory illness (CVD) was dominant (22\%) in Point Fortin and only 13\% in Port of Spain. Diabetes appears to also be significant in Point Fortin and much less in San Fernando and Port of Spain. It is curious to encounter such regional variations. Assuming that people go to the nearest facility when the seek hospital care, there are significant regional variations of NCDs on Trinidad. There are several possible explanations: there is possibly more elderly in the region, perhaps more obesity, or a different ethnic group near that particular facility. It also could be a case of miscod- 
ing by the hospital or any number of other possibilities. Likewise, in the Sangre Grande facility, digestive and respiratory illness accounted for the majority of hospital stays but represented a much smaller volume at the other facilities. Again, while likely explanation may exist, it appears that different NCDs prevail in different areas. This warrants further investigation

\section{SUMMARY}

The disease burden of Trinidad is equal to the burden of higher income countries. The small size limits natural, economic, human and infrastructure resources and therefore limits the ability of SIDS to effectively combat NCDs. Although there are a number of medical schools throughout the region, there remains a shortage of trained medical doctors on many islands, including Trinidad. This shortage impacts access hospital services for tens of thousands on the island.

Penchansky's five dimensions of access are all challenging on the island. The first, availability, defines numbers of providers such as physicians and hospital facilities in relation to the demand for their services. On Trinidad, the availability barrier is rooted in the shortage of physicians. This study revealed that the population to provider ratio was excessive in many areas. The second dimension, geographic accessibility, is a barrier for approximate 71,500 people who live outside the 15 mile zone from each of the four hospitals and experience excessive time and excessive distances to receive hospital care.

Accommodation, the degree that services meet the needs of patients and include hours of service, waiting times, appointments and scheduling, is also a barrier on Trinidad, again due to provider shortages. Research has documented that patient satisfaction is low [11-14].

Acceptability impedes access on the island due to mixed ethnicity, language and culture differences. Approximately $45 \%$ of the population are Indian, $45 \%$ African, and $10 \%$ other ethnicities. It is often difficult, for example, for an African to locate a physician that understands the African culture.

Affordability is a person's ability to pay for services and includes insurance coverage. Due to limited resources, there are also limited employments, insurance and affordability that become barriers.

In other words, all five barriers as outlined by Penchansky and Thomas are operating on the island of Trinidad and impact the ability of health care officials to effectively reduce the burden of NCDs [16]. Although Trinidad has made progress toward its commitment to the Port of Spain Declaration, there is additional work to complete to reach the country's goals in combatting the increase of NCD deaths.
Additional research is needed to evaluate access to clinics in the health districts with updated figures. However, many government agencies that collect and manage the data are reluctant to share that information for a variety of reasons. With more cooperation and access to information, the human resource shortage in the region would be greatly abetted by others. Many researchers in the region have requested that organizations make spatial data available. Unfortunately, to date, many Caribbean SIDS often are not willing or able to provide these necessary items due to limited size, as well as limited human, economic and technology resources.

Further research is also needed regarding the regional variations in illnesses reported by the hospital discharge summaries. Are these variations indeed representative of the populations living near these facilities? If so, additional clinic hours and educational programs would be valuable interventions for maintaining healthy communities and minimizing hospital use.

\section{ACKNOWLEDGEMENTS}

A special note of acknowledgement is due to the University of the West Indies, St. Augustine Campus and Dr. Bheshem Ramlal for shapefiles, physician and community data.

\section{FUNDING ACKNOWLEDGEMENTS}

This study was significantly aided financially by a grant from Middle Tennessee State University and the Faculty Research and Creative Activity Committee grant. The grant provided travel expenses to Trinidad-Tobago in 2011 and 2012.

\section{REFERENCES}

[1] World Health Organization (WHO) (2013) Chronic illnesses.

http://www.who.int/topics/chronicdiseases/factsheets/en/ index.html

[2] Population Reference Bureau (2013) Noncommunicable diseases and youth: A critical window of opportunity for Latin America/Caribbean. Policy Brief, Population Reference Bureau.

[3] Dachs, J., Norberto, W., Ferrer, M., Florez, C., Elisa, B., Aluisio, J.D., Narváez, R. and Valdivia, M. (2002) Inequalities in health in Latin America and the Caribbean: Descriptive and exploratory results for self-reported health problems and health care in twelve countries. Revista Panamericana de Salud Pública, 11, 335-355. http://www.scielosp.org/scielo.php?script=sci_arttext\&pi $\mathrm{d}=$ S1020-49892002000500009\&lng=en\&tlng=en.10.1590/ $\underline{\mathrm{S} 1020-49892002000500009}$

[4] Naomar, A.-F., Ichiro, K., Alberto, P.F. and Norberto, W.D.J. (2003) Research on health inequalities in Latin America and the Caribbean: Bibliometric analysis (19712000) and Descriptive Content Analysis (1971-1995). American Journal of Public Health, 93, 2037-2043. 
http://dx.doi.org/10.2105/AJPH.93.12.2037

[5] Montenegro, R.A. and Carolyn, S. (2006) Indigenous health in Latin America and the Caribbean. Lancet, 367, 18591869. http://dx.doi.org/10.1016/S0140-6736(06)68808-9

[6] Hospedales, C., James, S., Alafia, T., Cummings, R., Gollop, G. and Greene, E. (2011). Raising the priority of chronic noncommunicable diseases in the Caribbean. Revista Panamericana de Salud Pública, 30, 393-400.

[7] Perel, P., Casas, J.P., Ortiz, Z. and Miranda, J. (2006) Noncommunicable diseases and injuries in Latin America and the Caribbean: Time for action. PLOS Medicine, 3, e344. http://dx.doi.org/10.1371/journal.pmed.0030344

[8] Ferguson, T.S., Tulloch-Reid, M.K., Cunningham-Myrie, C.A., Davidson-Sadler, T., Copeland, S. and Lewis-Fuller, (2011) Chronic disease in the Caribbean: Strategies to respond to the public health challenge in the region. What can we learn from Jamaica's experience? West Indian Medical Journal, 60, 397-411.

[9] Gulliford, M.C., Ariyanayagam-Baksh, S.M., Bickram, L., Picou, D. and Mahabir, D. (1997) Social environment, morbidity and use of health care among people with diabetes mellitus in Trinidad. International Journal of Epidemioogy, 26, 620-627. http://dx.doi.org/10.1093/ije/26.3.620

[10] Ariyanayagam-Baksh, S.M., Bickram, L., Picou and D., Mahabir, D. (1995) Counting the cost of diabetic hospital admissions from a multi-ethnic population in Trinidad. Diabetic Medicine, 12, 1077-1085. http://dx.doi.org/10.1111/j.1464-5491.1995.tb00424.x

[11] Bourne, P.A. (2009) Socio-demographic determinants of health care-seeking behaviour, self-reported illness and self-evaluated health status in Jamaica. International Journal of Collaborative Research on Internal Medicine \& Public Health, 1, 101-130.

[12] Singh, H., Haqq, E.D. and Mustapha, N. (1999) Patients' perception and satisfaction with health care professionals at primary care facilities in Trinidad and Tobago. Bulletin-World Health.

[13] Bourne, P.A. and Joan, R. (2009) Good health status of rural women in the reproductive ages. International Journal of Collaborative Research on Internal Medicine \& Public Health, 1, 132-155.

[14] Bourne, P.A. (2009) A theoretical framework of the good health status of Jamaicans: Using econometric analysis to model good health status over the life course. North American Journal of Medical Science, 1, 86-95.

[15] Lee, J., Wolch, J.R. and Walsh, J. (1998) Homeless health and service needs. Putting Health into Place. Syracuse University Press, Syracuse.

[16] Penchansky, R. and Thomas, J.W. (1981) The concept of access: Definition and relationships to consumer satisfaction. Medical Care, 19, 127-140. http://dx.doi.org/10.1097/00005650-198102000-00001

[17] Trinidad-Tobago Ministry of Health. Annual Statistical Report 2004-2005. http://www.health.gov.tt/sitepages/default.aspx?id=122

[18] World Bank (2013) http://data.worldbank.org/topic/health

[19] Bureau of Primary Health Care (BPHC) (2012) Published in The Federal Register, 77. Government Accounting Office, Washington DC. 